\title{
Research on Food security and Pricing on adjoining region of Shanghai Ocean Uni- versity and Shanghai Maritime University
}

\author{
Sun Man ${ }^{1, a}$ Jiang Xin ${ }^{1, b}$ Wang Chaojin ${ }^{1, c}$ \\ ${ }^{1}$ Shanghai Ocean University, China $\quad{ }^{c}$ cjwang@ @ shou.edu.cn +8615692165891
}

\begin{abstract}
This paper aims to investigate the Food security and Pricing in the adjoining region of Shanghai Ocean University and Shanghai Maritime University. Investigators came up with some suggestions about supervision and management based on the survey and analysis to profit local consumers.
\end{abstract}

Keywords: adjoining region; food security; food prices; monitoring system

\section{Introduction}

Food is one of the factors in Maslow's hierarchy of needs ${ }^{[1]}$. There is an ancient Chinese saying which implies that, "Bread comes first". According to "Food Hygiene Law of the People's Republic of China"(1995), food means any substance that has been processed or not processed, that is suitable for eating and/ or drinking, including substances used as food and medicine, excluding substances solely used as medicine. Without a doubt, instead of food quality, safety and prices problem, hunger is no longer the public's facing focus in modern civilized society. It is a noticeable fact that students are lack of knowledge about food security and have no main source of living. Regarding the situation, interviewers, the team from SHOU, decided to study the issues concerning food security and pricing in the adjoined region since they inseparability influence people's daily life.
And combining the three aspects of guiding ideology of food security law system ${ }^{[2]}$, some suggestions would be provided to improve the present condition in the university town.

Adjoining region is situated between Shanghai Ocean University and Shanghai Maritime University, where teachers, students and surrounding residents live. This area has a significant economic benefit due to lacking of competition.

The survey achievement indicates that, this area has more than 20 cafeterias or stalls, "refreshment sellers" and countless supermarkets. The main reasons for students dining in this area are ut sequitur: (1) Convenient Location: short distance (2) Superiority of food: varieties of food (3) Social campus network: for parties. Meanwhile questionnaire reflects that food health assessment in this area is not high, $34 \%$ of interviewees doubt the food security, and $67 \%$ believe that this area's restaurants are overpriced. Therefore, it is necessary to conduct a thorough investigation.

In this paper researchers analyze the food safety which means the assurance that the food is nontoxic, harmless, and compliant with reasonable nutritional requirement, and will not cause any acute, chronic and potential hazards to human health ${ }^{[3]}$ and pricing strategy in Shared business circle of SHOU and SMU. Meanwhile, based on a market economy ${ }^{[4]}$, it is promising to promote the food security and make the pricing more reasonable. A win - win sit- 
uation for the consumers and entrepreneurs would be promoted in this paper.

\section{Research methods}

1) As-

pect of food security: collection, identific ation and analysis. 2) The food pricing: specific survey and questionnaire on networks ${ }^{[5]}$. With food, store costs, food security and other factors, the team make reasonable suggestions on pricing strategies for different kinds of food in this area.

\section{Grade:}

First, the details of classification on sanitary condition and food security of lunchrooms in AR (Adjoined Regions) are as following: the Smiling routine are labeled as the qualified lunchrooms, the Emotionless mundane ones and the rest unascertained, as the standardized sanitary discrimination on AR. Then the categorizations on foods are based on the measures of food manufacturing, as the specimens from Hotpots, Barbecues, Fried, Dishes, Soft drinks and alcohol, etc. The final analyses would be instituted on the outcomes of whole investigation on AR.

\section{Results and Discussion}

From proprietors' point of view

In mid-November, the team conducted an online poll about where the consumers believe food safety problems are more likely to happen, results as following:

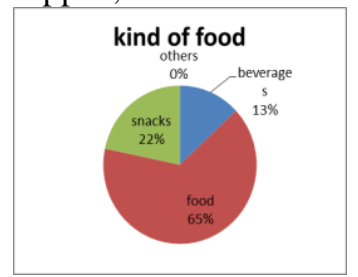

All restaurants have a Catering Service License; but not all employees have health certificates. Most restaurants are family business running mode, and have a low holder rate. Many restaurants have no food security management system and food security administrator. Disposable plastic products are widely used and there are sterilization equipment being applied.
Food security issues seem significant. The survey shows that employees lack the knowledge of food security, for instance, they wore overalls for a long time which never be sterilized.

Restaurants in this area are mostly not fully qualified. They should solve the hidden danger with related departments and provide the students with affordable, healthy and delicious dining.

From students' point of view

Students should strengthen the awareness and knowledge of food security. In the investigation, what has been discovered:

1) People pay little attention to identification note when buying food products. 2) Few people care the content of "Food security Law" 3) Less access to information. 4) Few report or complaint to the relevant agency.

Students as main consumer group in this area that has no source of income. More than $60 \%$ of the students feel the food are overpriced and more than $40 \%$ of them believe that the acceptable price of a meal is $¥ 10$ to $¥ 20$. However, the actual cost is over $¥ 20$, which is far beyond the affordable prices.

\section{Conclusion}

4.1. Food security cannot be ignored.

The survey result displays, consumers doubt the food security problems do exist. There are a lot of safety risks in the restaurants. The reasons are as follows: business operators have no awareness of food security. For the costs, they buy some cheap but unidentified materials. And there is no effective monitor system to ensure the food security. The employees also lack the Essential knowledge and training. Food Safety Risk Assessment is as necessary as publicizing risk information ${ }^{[6]}$.

On the other hand, students don't know how to get access to safe food. They often prefer pay attention to the convenience and taste rather than its quality or safety. 
Food security problems cannot be ignored. The existence of safety risks is like a time bomb endangering the health of students. Effective measures must be taken before troubles burst out.

\subsection{The cost}

In the basic theory of market-based pricing system, enterprises are the main part of pricing. Its goal is to maximize profit. After the analysis of the survey results, researchers find that the cost is an important reason to determine the price ${ }^{[7]}$, a good pretense for operators. Scholars also know the question about college town development is capital.

High logistics costs: With the development of cities, counter-urbanization phenomenon appears, and the logistics costs increase exponentially with the development of public transportation. The more convenient the transportation is, the lower logistics costs will be. Lower logistics costs come from the developed regions, and vice versa. These two universities located in remote area.

High cost of rent: The high cost of rent is not only the most often mentioned factor in interviews, but also the practical problem. The monopoly position for college towns leads to high rents.

\subsection{Become a rational consumer}

In the survey, based on Statistical data, author builds a multivariate linear regression model and gets a lot of obvious conclusions. However, there are also many phenomena which are hard to understand. When asked about food price of adjoining region, $75 \%$ of interviewees believe the price is too high, $25 \%$ think it is moderate. This suggests that the price is relatively high in people's minds. However, people agree that high price could be acceptable for the taste and sanitary condition. In fact, with the high prices, no student has

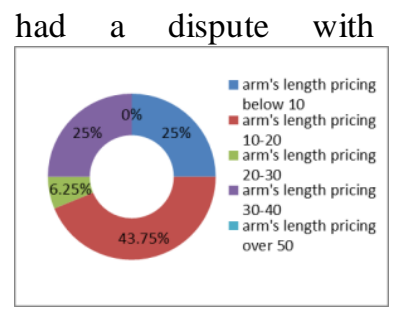

The average consumption of a meal in adjoining region occurred near the average. It means different people in the adjoining region have different consumption ability. Yet, everyone thinks himself has paid much more. From the supply and demand perspective, consumers are not satisfied with the products ship-owner offered in its willingness to pay a price range of products, in turn, the supply of products in the same price did not meet the consumers' expectations

In conclusion, students of SHOU and SMU have problems in food consumption in this area. Passiveness represents itself in the forced adaptation submitted with overweighing prices. And negative treatments without rational proposals or protesting actions. Meanwhile the extreme subjective is revealed in personal favors.

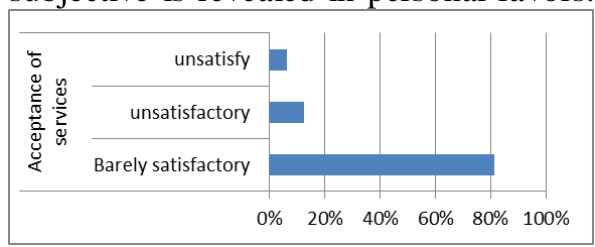

After all, these phenomena were perfectly observed upon the pursuits of savor and unconcerned choices of vendors.

\subsection{Advice}

College students should be on a scientific diet and rational consumption. The relevant administrative agency should strengthen supervision on the canteen. This report puts forward the following countermeasures for food security and food prices around the schoolyard.

Suggestions on students: 1) get more information about the food security 2) Refuse unsafe and unhygienic food 3) Eliminate bad consumption behaviors and ad- 
vocate moderate and civilized consumption.

Suggestions on schools and relevant agency: 1) Schools should pay attention to improve the students' recognition of the false ads and fake products. They also should vigorously promote the legal consciousness of college students. 2) The relevant agencies should always check whether the catering industry's licenses are complete and valid ${ }^{[9]}$. 3) Health department should examine the restaurant regularly.

Operators shall bear the obligation to prevent others from suffering injury. 1) The agencies shall set up bulletin boards to publish results of examination of regular active ingredients ${ }^{[10]}$. 2) To set up a monitoring group, regularly inspect for health and other aspects of staff, randomly check some possible causes of the food security problem in the work place ${ }^{[11]}$.

Supervise the operators to strengthen management, establish and improve the food security system, establish and improve the food security system coordination, make clear responsibilities of the mandatory requirements, full-time food hygiene manager in implementing the system. The practitioners should be supervised in strict compliance with the regulations on food security and the management system requirements must be developed ${ }^{[12]}$. The protection of individuals engaging in food production should be strengthened.

\section{Summary}

1) The proprietor should strengthen selfregulation and self-discipline consciousness.

2.) The relevant departments should strengthen penalties and ensure each business is operating under people's supervision with reasonable pricing and food safety condition.

3) Schools should encourage teachers and students to provide suggestions about adjoining region.

\section{Reference}

[1]Maslow, Motivation and Personality, China Renmin University Press Co., LTD, 2009

[2]Legislative Affairs Office of the State Council, Food Safety Law of the People's Republic of China, China Legal Publishing House, 2013

[3] Tao Xianfu,"The discussion about the food security and health management", Journal of Environmental Management College of China, 2010

[4] Zhou Jiehong,"Study of the problem of food security management and progress ".School of Management ZheJing University, 2004

[5] Yuan Wensong,"Innovation price investigation and promote sound and rapid economic development". China Price Supervision and Check, 2009

[6]Li Huai,"Food security regulatory system in developed countries and Implications to China", Dongbei University of Finance and Economics, 2005

${ }^{[7]} \mathrm{Su} \mathrm{Su}$, "The Research on Product Price Theory and Pricing Method". Chongqing University, 2001

${ }^{[8]}$ Tan Rongqing, "The analysis of consumer behavior and psychology of contemporary college students",Chinese business magazine (the first half), 2010 (02).

${ }^{[9]}$ Li Zhengzhong."To construct the food security project",China Food Quality News, 2005

[10] Song Zongyu,"Theory of security obligation of the operator - by "crying servant of god and the embarrassment of legal thinking ", School of Law Chongqing University, 2008

[11]Gao Wenzhang,"Thinking about the university canteen food prices" ,Prices Month, 1994

[12] Xia Ying, "food security: from the quality standard system to integrated supply management of supply chain", Institute of agricultural economics and development, 2001 